\title{
Absorción renal de agua. Del nefrón aislado a los canales de agua a Aquaporinas.
}

\author{
WHITTEMBURY Guillermo*, HERNANDEZ Celia Sofía* \\ * Instituto Venezolano de Investigación Científicas IVIC, Caracas Venezuela.
}

\section{RESUMEN}

Se revisan brevemente: Los sitios de absorción del filtrado glomerular en diversos segmentos del nefrón, los sitios de acción de la hormona antidiurética (HAD), los conceptos que llevan a proponer que existen canales de agua en el túbulo renal proximal. llamados ahora Aquaporinas (AQP), algunas características biofísicas (diámetro equivalente y longitud) del filtro de selectividad de la AQP-1 en el túbulo renal proximal, estructura molecular de las AQP, algunas características de las AQP- 1-5, localización de las AQP 1-4 en el nefrón y algunos ejemplos de "fisiopatología molecular", que muestran que fallas genéticas en etapas de la acción de HAD en los túbulos colectores de los nefrones permiten describir varias formas de "diabetes insípida" renal. Hay métodos para dosar AQP-2 en orina. Esto simplificará el diagnóstico diferencial entre diversas formas de diabetes insípida. Estos hallazgos han sido posibles por los avances recientes en la biología molecular de las AQP. Sólo se citan algunas referencias críticas. (Rev Med Hered 1997; 8: 158-161)

PALABRAS CLAVE: Absorción de agua, riñón, canales de agua, Aquaporinas, fisiopatología molecular, diabetes insípida.

\section{Sitios de absorción de agua a lo largo del Nefrón.}

Diversos métodos para estudiar la función renal, señaladamente los de micropunción y depuración permitieron asegurar antes de 1950 que en los mamíferos un $80 \%$ del agua que forma el filtrado glomerular, FG, (isosmótico con el plasma del animal) se absorbe en el túbulo renal proximal. No hay absorción de agua en el segmento delgado del asa de Henle. El resto del filtrado se absorbe en los segmentos mas distales del nefrón, posteriores al asa de Henle, particularmente en los túbulos colectores, en donde la acción de la hormona antidiurética (HAD) es fundamental para la absorción del 15\% restante del FG. Así se elimina un volumen de orina final de un 1 al 2\% del FG. En estas circunstancias la orina es hiperosmótica en relación al FG (o al plasma de animal). Cuando no hay secreción de la HAD o esta secreción es pequeña la orina de es hiposmótica en relación al FG y su volumen puede ser tan alto como 10 a $15 \%$ de este último. 
En los años 50 medidas de osmolalidad de muestras obtenidas por micropunción de los vasos rectos de la obtenidas por micropunción de los vasos rectos de la papila renal y de las asas de Henle y túbulos colectores mostraron que el intersticio, asas de Henle y los vaso rectos y en orquilla de la papila renal son "muy" hiperosmóticos en relación al FG. Esto probó que el mecanismo de contra-corriente explica la formación de orina concentrada en presencia de HAD y diluída en su ausencia. Se propuso que en presencia de HAD había un aumento de la permeabilidad al agua de la pared de los túbulos colectores permitía el equilibrio del líquido (u orina primaria) que circulaba en su interior con el líquido hiperosmótico intersticial papilar produciendo así orina hiperosmótica. En ausencia de HAD ese aumento de permeabilidad desaparecía. Los túbulos colectores eran prácticamente impermeables al agua y la orina mantenía entonces la baja osmolalidad de la "orina primaria" que circulaba por el túbulo renal distal. En estas circunstancias la orina primaria hiposmótica que circula dentro de los túbulos colectores no se equilibra con el intersticio hiperosmótico.

Recién en 1980 Bourguet y colaboradores (ver ref 13 para mayores detalles) haciendo microscopia electrónica de criofractura encontraron en ausencia de HAD unas estructuras "quasicristalinas" en microvesículas subyacentes a la membrana apical de las células de la vejiga urinaria de anfibios que es un modelo para estudiar la acción de la HAD. En estas condiciones la vejiga urinaria es prácticamente impermeable al agua. En presencia de HAD esas estructuras se observan adosadas a la membrana apical. En estas condiciones la vejiga urinaria es muy permeable al agua, incluso en los tejidos fijados con glutaraldehido. Estas observaciones fueron luego confirmadas en túbulos colectores.

\section{Hipótesis de la "lanzadera" (transbordador shuttle) en el túbulo colector para explicar el mecanismo de acción de la HAD.}

Wade propuso la hipótesis de la "lanzadera" (13). En ausencia de HAD los "canales de agua" que corresponderían a las estructuras quasicristalinas mencionadas arriba estarían subyacentes en las microvesículas. La membrana apical no seria permeable al agua por carecer de canales de agua (las estructuras quasicristalinas). En presencia de HAD las microvesículas se adosarían a la membrana apical; las estructuras quasicristalinas (canales de agua) ahora en contacto con la superficie apial conferirían a la membrana apical a la permeabilidad al agua necesaria para la equilibración de la "orina primaria" mencionada arriba. Pero no había todavía métodos que mostraran la presencia o no de canales de agua en el túbulo renal.

\section{Demostración de la existencia de canales de agua en la membrana de las células del túbulo renal proximal.}

El agua puede atravesar las membranas celulares en una de dos formas o en ambas (1). A través de la bicapa lipídica que forma la membrana celular. El grado de permeabilidad depende de la composición de los lípidos de esa bicapa. Este paso de agua tiene una alta 
energía de activación (Q10) porque la interacción entre moléculas de agua y cadenas lipídicas es muy grande (2). Por estructuras especiales o canales de agua. En este caso la permeabilidad al agua de cada canal puede variar de acuerdo a la estructura del mismo y la permeabilidad por $\mathrm{cm} 2$ de membrana celular dependerá de la densidad de esos canales en la membrana. La energía de activación de la permeabilidad por los canales será seguramente baja, porque no se espera gran interacción entre las moléculas de agua que permean el canal y las paredes del mismo. Si los canales son proteínicos se espera que algunos reactivos (por ejemplo de grupos sulfidrilos) alteren la permeabilidad de estos. Entre 1980 y 1984, Whittembury y colaboradores (14) desarrollaron métodos para estudiar estas posibilidades. Encontraron que el $90 \%$ de la permeabilidad osmótica (al agua) de la membrana peritubular de las células de los túbulos renales proximales se debía al paso de agua por canales de agua y era inhibida por reactivos de grupos sulfidrilos como los mercuriales, mostrando que los canales de agua eran proteínas. El 10\% de la permeabilidad era por tránsito de agua por la capa lipídica.

\section{Características biofisicas del filtro de selectividad de los canales de agua en células del túbulo renal proximal.}

Aunque el canal de agua se describe como una estructura "equivalente de sección cilíndrica o rectangular de unos 40 A de longitud (para que atraviese la membrana celular) es difícil pensar que la sección sea uniforme.

Más lógico es concebir que haya una parte mas angosta o selectiva en el canal que discrimina entre diversas partículas por su tamaño o carga. Esta parte se denomina "filtro de selectividad". Estudios de tamizado molecular muestran que aún moléculas tan pequeñas como úrea y acetamida no atraviesan el canal de agua. La formamida sí lo hace. Por el tamaño de estas moléculas se calcula que la sección del "filtro de selectividad" debe tener un diámetro de unos 4.5 A si es cilíndrica, o de unos 4.0 x 5.2 A si es rectangular (4). Como el diámetro de una molécula de agua es $3 \mathrm{~A}$, en una región de las dimensiones que se mencionan para el filtro de selectividad, las moléculas de agua deben estar una tras otra, esto es un "fila india"; porque dentro de esta parte del canal unas moléculas de agua no pueden adelantar a las otras. Recientemente, usando la teoría bimodal de la osmosis de Hill hemos calculado que unas 2 a 3 moléculas de agua forman esa "fila india" en el filtro de selectividad del canal. O sea que el largo del filtro de selectividad debe ser entre 6 y 9 A si las moléculas de agua se tocan unas a otras; pero la longitud puede ser algo mayor si hay espacios entre ellas (15).

\section{Biología molecular de los canales de agua.}

En 1992 Agre y colaboradores (9) describieron en glóbulos rojos la estructura molecular del canal de agua, ahora llamada por consenso "aquaporina" (AQP). La AQP de glóbulos rojos, similar a la del túbulo renal proximal, se denomina AQP-1. Pesa $28 \mathrm{KD}$, y su secuencia de aminoácidos se conoce. 
Cada AQP-1 tiene 6 segmentos (a hélice) transmembranales numerados del 1 al 6 . El terminal amino va seguido de: el segmento 1, una asa extracelular A, el segmento 2, una asa citoplasmática $\mathrm{B}$, el segmento 3 , una asa extracelular $\mathrm{C}$, el segmento 4, una asa intracelular D, el segmento 5. una asa extracelular E, el segmento 6 y el terminal carboxilo intracelular. Los segmentos 1, 2 y 3 y las asas A, B y C prácticamente se repiten en la segunda mitad de la molécula; en otras palabras la primera y la segunda mitad de la molécula están "en tandem". El asa B y el asa E (que son parecidas) tienen cada una, una secuencia NPA (asparragina. prolina, alanina).

Se concibe que las asas B y E entrelazadas dentro de los 6 alfa hélices hagan el filtro de selectividad. Hay 4 cisteinas, pero sólo la 189 (asa E) es la sensible a la acción de los mercuriales. Pequeñas variaciones en el segmento carboxilo terminal y en las asas B y D, caracterizan las AQP 2, 3 y 4, renales respectivamente.

Cada AQP-1 funciona como un canal de agua independiente. Pero cuatro hacen un tetrámero que forma el grupo fundamental de AQP-1. En el tetrámero sólo una AQP-1 está glicosilada. Hay otras AQP, también en tejidos vegetales.

\section{Localización de las AQP 1,2,3 y 4 a lo largo del nefrón.}

La AQP-1 está en las membranas basolaterales y apicales de las células del túbulo proximal. en los segmentos S1, S2 y S3 (o segmentos proximal recto, descendente). No se conoce que sea regulada.

No se ha detectado AQP en el asa de Henle. Es interesante constatar que no se encuentra $\mathrm{AQP}$ en los segmentos del nefrón que no son permeables al agua (7).

La AQP-2 está en la membrana apical de las células principales del túbulo colector. Hibridización in situ examinada con microscopio de luz y con microscopio electrónico muestra que es regulada por $\operatorname{HAD}(7,8)$ en la forma propuesta por la hipótesis de la "lanzadera" descrita arriba (13).

Recientemente, se ha encontrado que hay un elemento que responde al AMP cíclico (cAMP Responsive Element) en el promotor génico de AQP-2. Es un elemento cis clave para la regulación transcripcional del gen, mediado por AMP cíclico y puede ser importante para la regulación in vivo de la expresión de la expresión de AQP-2 en los estados de deshidratación (6).

La AQP-3 está en la membrana basolateral de los túbulos colectores. Su expresión es regulada los animales deshidratados $(2,3)$.

La AQP-4 esta en la membrana basolateral de los túbulos colectores a nivel de la papila más profunda. Su expresión es regulada en los animales deshidratados (12).

\section{Algo de fisiopatología molecular.}


Los siguientes son sólo algunos ejemplos del progreso logrado en el conocimiento de las AQP y del manejo renal de agua por el progreso de la biología molecular.

Los enfermos que reciben Li2CO3 (por ejemplo en el tratamiento de psicosis maniacodepresiva) tienen menor expresión del RNA mensajero de AQP-2. Esto se corrige con administración de HAD.

La diabetes insípida hipofisaria ha sido siempre conocida. Los conocimientos de biología molecular aclaran nuestras ideas sobre la diabetes insípida renal (DIR). Se sabe ahora que hay diversos tipos de DIR por distintas fallas genéticas en el receptor de HAD (9). Hay DIR de varios tipos por fallas en el mecanismo transportador de la señal del AMP cíclico (1). Otros casos de DIR se ha descrito por fallas en el mecanismo de "lanzadera". Finalmente hay otros por fallas en la estructura misma de AQP-2 (1). Hay en estudio un método para medir AQP-2 en la orina. Esto ayudará a diferenciar entre diversos tipos de diabetes insípida $(5,10)$.

\section{REFERENCIAS BIBLIOGRÁFICAS}

1.Deen PMT, et al. Water channels encoded by mutant aquaporin-2 genes in nephrogenic diabetes insipidus are impared in their cellular routing. J Clin Invest 1995;95: 2291-2296.

2.Ecelbarger CA, et al. Aquaporin-3 water channel localization and regulation in rat kidney. Am. J. Physiol. 1195;269: F663-F672.

3.Echevarría M, et al. Cloning and expresion of AQP3, a water channel from the medullary collecting duct of rat kidney. Proc Natl Acad Sci USA 1994;91:10997-11001.

4.Gutierrez AM, et al. The proximal straght tubule basolateral cell membrane water channel: Selectivity characteristics J. Membrane Biol 143: 189-197.

5.Kanno K. et al (1995) "Urinary excretion of aquaporin-2 in patients with diabetes insipidus" New EngI J Med 332: 1540-1545.

6.Matsumura Y, et al. Transcriptional Regulation of Aquaporin-2 water channel gene by cAMP. J Am Soc Neprol 1997;8: 861-867.

7.Nielsen S, et al. CHIP 28 water channels are localized in constitutively water permeable segmens of nepron J Cell Biol 1993;120: 37, 1-383.

8.Nielsen S, et al. Vasopressin increases water permeability of kidney collecting duct by inducing translocation of aquaporin-CD water channels to plasma membrane. Proc. Natl Acad Sci USA1993; 92: 1013-1017.

9.Preston GM, et al. Appearance of water channels in Xenopus oocytes expressing red cell CHIP28 protein. Science 1992: 385-387.

10.Rai T, et al. Urinary excretion of Aquaporin-2 channel protein in human and rat. J Am Soc Nephrol. 1997; 8: 1357-1362.

11.Rosenthal W, et al. Molecular identification of the gene responsible for congenital nephrogenic diabetes insipidus. Nature 1992; 359: 233-235.

12.Terris J, et al. Distribution of Aquaporin-4 water channel expression within rat kidney Am J Physiol 1995; 269: F775-F785.

13.Wade JB, et al. ADH action: evidence for a membrane shuttle hypothesis Ann NY Acad Sci 1981; 372: 106-117. 
14. Whittembury G, et al. Effect of pCMBS and temperature on cell water osmotic permeability of proximal straight tubules. Biochim Biophys Acta 775: 365-3 73.

15. Whittembury G, et al. Length of the selectivity filter of aquaporin-1" Biology of the Cell 1997; 89.

\section{Agradecimientos:}

Este artículo esta dedicado al Dr. Carlos Monge C. quien tanto hizo para avanzar la Nefrología en el Perú formando un grupo unido de fuertes discípulos. Además hizo esfuerzos increíbles para formarse como investigador enseñándome a plantear hipótesis y a hacer experimentos con claros raciocinios que pudieran servir para aceptarlas o rechazarlas. Su amistad de tantos años, su dedicación y ejemplo años siguen siendo invalorables.

\section{Correspondencia:}

G. Whittembury

IVIC, Apdo 21827, Caracas 1020-A Venezuela;

$\mathrm{Tel}+$ (58 2) 504-1120; Fax + (58 2) 504-1093

E-mail: gwhitt@cbb.ivic.ve 